\title{
O EFEITO DO TIPO DE PRODUTO E DAS CAPABILIDADES LOGÍSTICAS SOBRE O CICLO DO PEDIDO
}

\author{
Roberto Giro Moori* \\ rgmoori@uol.com.br \\ Ester Felix* \\ ester.felix@uol.com.br \\ Eliacy Cavalvanti Lelis* \\ eliacylelis@gmail.com \\ Adilson Caldeira* \\ adilson.caldeira@mackenzie.br \\ *Universidade Presbiteriana Mackenzie - São Paulo, SP
}

http://dx.doi.org/10.1590/1413-2311.0112014.47436

Recebido em 27/03/2014

Aprovado em 06/03/2015

Disponibilizado em 01/04/2015

Avaliado pelo sistema double blind review

Revista Eletrônica de Administração

Editor: Luís Felipe Nascimento

ISSN 1413-2311 (versão on line)

Editada pela Escola de Administração da Universidade Federal do Rio Grande do Sul.

Periodicidade: Quadrimestral

Sistema requerido: Adobe Acrobat Reader.

\section{RESUMO}

A logística admite liberdade na seleção de locais de produção como meio para vantagens competitivas. Graças a transporte rápido, armazenagem e sistema de informação é possível, por exemplo, em pleno inverno, adquirir frutas tropicais ou qualquer outro produto sazonal da América do Sul em países do hemisfério norte. Nesse sentido, as capabilidades logísticas assumem papel importante para a rapidez no atendimento e oferta de produtos de preços baixos aos consumidores. Com base nesse contexto, realizou-se este estudo com o objetivo de verificar o efeito do tipo do produto exportado (commodity ou industrializado) e das capabilidades logísticas sobre o ciclo de entrega de pedido. Para tanto, realizou-se uma pesquisa exploratória do tipo quantitativo junto a 56 profissionais atuantes na gestão de logística e cadeias de suprimentos em empresas exportadoras de café, açúcar, soja, carne e bens de capital. A coleta de dados ocorreu por meio de um questionário, previamente, submetido a pré-testes junto a sete gestores de empresas exportadoras de commodities e produtos industrializados para refinamento e validação de conteúdo. Os dados, tratados pelas técnicas da regressão linear e ANOVA para dois fatores, revelaram não haver interação entre tipo de produto exportado e capabilidades logísticas. Este resultado levou a deduzir que outros fatores como taxa de câmbio, infraestrutura logística (portos, rodovias, armazéns e terminais de transbordos) podem estar influenciando na eficiência logística, necessitando assim, de um maior aprofundamento da pesquisa para se ter maior conhecimento do assunto.

REAd | Porto Alegre - Edição 80 - N 1 - janeiro/abril 2015 - p. 141-169 
Palavras-chave: gestão logística; ciclo do pedido; capabilidades logísticas; exportação brasileira; desempenho superior.

\title{
THE EFFECT OF THE TYPE OF PRODUCT AND OF THE LOGISTICS CAPABILITIES ON ORDER DELIVERY CYCLE
}

\begin{abstract}
Logistics allows freedom in the production's sites selection to obtain competitive advantage. Thus, due to fast shipping, warehousing and information systems it is possible, in the winter, for instance, buy tropical fruits or any other seasonal product from South America in countries located in the northern hemisphere. In this sense, the logistics capabilities play an important role for the quick responsiveness and low cost to consumers. In this context, this study aimed to answer how the different types of exported products (commodities or industrialized) and the logistics capability affects on the delivery cycle order. For thus, it were realized a exploratory research of the descriptive type with 56 logistics and supply chain managers related to coffee, sugar, soy bean, meat and capital goods companies. The data collection tool used was a questionnaire that, at first, was submitted to pre-tests for refinement and contents validation with seven managers related to commodity and industrialized product companies. The data collected were treated by linear regression and two-way ANOVA and showed that there is no relation between the type of exported product and logistics capability on the delivery cycle order. This result led to the deduction that external factors such as exchange tax, logistics infrastructures deficiencies related to ports, highways, warehouses and transshipment terminals may be influencing in the logistic efficiency, requiring thus a further research to have more knowledge of the subject.
\end{abstract}

Keywords: logistics management; order delivery cycle; logistics capability; Brazilian exports; superior performance.

\section{EL EFECTO DEL TIPO DE PRODUCTO Y CAPABILIDAD LOGÍSTICA SOBRE EL CICLO DE PEDIDO}

\section{RESUMEN}

Logística permite libertad en la selección de sitios de producción para obtener ventaja competitiva. Así, gracias a el envío rápido, el almacenamiento y sistema de información es posible, por ejemplo, en invierno, adquirir frutas tropicales o cualquier otro producto de temporada de América del Sur en el hemisferio norte. En este sentido, la capabilidad logística asume papel importante para la capacidad de respuesta rápida de atención y de bajo coste para los consumidores. A partir de este contexto, el presente estudio tuvo como objetivo verificar el efecto del tipo de producto exportado (materia prima o procesado) y capabilidad logística en el ciclo de pedido. Para eso se realizó una investigación exploratorio descriptivo junto a 56 gerentes de logística y cadenas de suministro de empresas que exportan productos como el café, el azúcar, la soja, la carne y los bienes de capital. El instrumento de recolección utilizado fue un cuestionario, que antes, se sometió a pruebas previas para refinar y validar el contenido en siete directivos de las empresas que exportan productos de materias primas y productos industrializados. Los datos procesados por las técnicas de regresión lineal y ANOVA para dos

REAd | Porto Alegre - Edição 80 - N 1 - janeiro/abril 2015 - p. 141-169 
factores, no mostraron ninguna interacción entre el tipo del producto de exportación y capabilidad logística. Este resultado nos llevó a deducir que los factores externos, tales como deficiencias en la infraestructura logística relacionada a los puertos, carreteras, almacenes y terminales de transbordo, pueden estar influyendo en la eficiencia logística, por lo que requiere una mayor investigación para tener un mayor conocimiento de la materia.

Palabras clave: gestión logística; ciclo del pedido; capabilidad logística; exportaciones brasileñas; mayor rendimiento.

\section{INTRODUÇÃO}

As recentes tendências da produção global têm sido a de aumento da complexidade da cadeia de suprimentos e revigoramento da noção de que as práticas logísticas são elementos essenciais para as estratégias de negócios (STOCK; GREIS; KASARDA, 2000). As incertezas geradas pela globalização, que reduzem o tempo ciclo de vida dos produtos, também tem levado ciclos de entrega de pedido (lead time) a tempos menores. Entende-se por ciclo de entrega pedido o tempo decorrido entre o recebimento do pedido do cliente até a entrega do produto (CHRISTOPHER, 1999).

Segundo Bowersox, Closs e Stank (1999), nessa situação, em que a gestão das atividades operacionais se estende além dos limites das fronteiras da empresa, podem ser constatadas em empresas multinacionais ou em um conjunto de empresas alinhadas estrategicamente, que atuam em parceria, para capturar oportunidade específica de mercado. Em consonância com essa visão, Fugate, Mentzer e Stank (2010) argumentam que as empresas com extensão global são planejadas para providenciar um ciclo de entrega de pedido com agilidade, baixo custo e flexibilidade necessária para responder rapidamente às oportunidades de mercado.

A importância das atividades logísticas para a competitividade se revela nas diferentes categorias de produto que demandam diferentes cadeias de suprimentos (FISHER, 1997), práticas logísticas e tecnologias (LAMMING et al. (2000). Como exemplo de indústria que tem empregado novas práticas logísticas, em função da natureza do produto, para a melhoria do desempenho competitivo, pode-se mencionar a indústria de sucos, néctares e laticínios líquidos, cuja tendência é de comercialização de produtos sem embalagens, como commodities, quando o preço é fator decisivo para o comprador; ou embalados, quando a competitividade decorre do valor adicionado percebido pelo cliente (HAFFNER; LINTHICUM; PUNCHARD, 2014).

Quanto à influência da inovação tecnológica, esta é percebida como no caso do transporte ferroviário de minério de ferro, carvão e coque, em que ocorre o aumento da 
O efeito do tipo de produto e das capabilidades logísticas sobre o ciclo do pedido

quantidade transportada, em tonelagem, com a mesma infraestrutura, graças à modernização da sinalização e de controle da ferrovia (NEDER, 2013).

No que concerne à exportação de produtos brasileiros, a logística é considerada um componente crítico, requerendo atenção a aspectos como a ação sistêmica e integrada das funções internas e investimento em inovação tecnológica para encurtar o ciclo de entrega de pedido de produto para cliente do país estrangeiro.

Nesse sentido, em 2012, enquanto no Brasil os gastos em logística foram de 11,5\% do PIB, nos Estados Unidos não passaram de 8,7\% do PIB. Em termos de exportação de produtos brasileiros, em 2013 alcançou US\$242,2 bilhões e representou uma redução de $1 \%$ em relação a 2012 (MDIC, 2014). O modal marítimo é o mais utilizado no comercio internacional brasileiro e corresponde, aproximadamente, a 95\% do total exportado (FLEURY, s.d.). Segundo Rocha e Ferreira-da-Silva (2014), de um total de carga movimentada em 2009, pouco mais de 730 milhões de metros cúbicos, 59\% foram de carga a granel sólida, $27 \%$ de carga a granel líquida, $9 \%$ de carga conteinerizada e 5\% de carga geral. Para superar as dificuldades da prática da logística internacional, decorrentes de aspectos relativos a distanciamento geográfico, diversidade cultural, legislação e envolvimento de diversas empresas fornecedoras e subfornecedoras, as empresas dependem de suas capabilidades logísticas (BOWERSOX; CLOSS; COOPER, 2006).

Assim, considerando que as capabilidades logísticas têm papel importante na exportação dos produtos nacionais, e que, as decisões dos gestores logísticos podem impactar na eficiência do ciclo de entrega do pedido, definiu-se como problema de pesquisa a seguinte questão: o ciclo de entrega do pedido é influenciado pela interação entre o tipo de produto exportado e as capabilidades logísticas? O objetivo foi o de descobrir como o ciclo de entrega de pedido depende dos fatores: tipo de produto (commodities ou produto industrializado) e níveis de capabilidades logísticas (baixa, média ou alta).

O artigo está estruturado da seguinte maneira. Após a introdução, é apresentado o referencial teórico e hipóteses para o modelo estatístico relacionados a capabilidades logísticas, ciclo de entrega de produtos e a interação entre o tipo de produto e capabilidades. Na sequência são descritos os procedimentos metodológicos, a análise dos dados e resultados. Finaliza-se o artigo com a apresentação das considerações finais.

\section{REFERENCIAL TEÓRICO E HIPÓTESES}

Em ambiente de competição global, de um lado, tem surgido modelo de competência logística de classe mundial em que se destacam quatro capabilidades logísticas: 
posicionamento estratégico, integração, agilidade e medidas de desempenho (GOLDSBY; STANK, 2000). De outro, com a redução dos ciclos de vida dos produtos, os ciclos de entrega dos pedidos de produtos (lead time) também necessitam ser realizados em tempos cada vez menores e consistentes. Nesse sentido, o ciclo de entrega deve ser gerido com eficiência (BALLOU, 2006; DAVID; STEWART, 2009).

Todavia, exportar produtos com características diversas em peso, forma, estado (solido, liquido ou gasoso), volume e perecebilidade, envolvem decisões de gestão logística como escolhas de equipamentos, estiva, treinamento, modos de transporte, armazéns e instalações. De maneira simplificada, estas escolhas abarcam dois tipos de produtos: as commodities, embarcadas a granel, e os industrializados, embarcados em containers.

Portanto, a depender da interação (ou combinação) do tipo de produto e das capabilidades logísticas, pode-se produzir um efeito no ciclo de entrega do pedido.

O modelo estatístico representativo da interação entre o tipo de produto e capabilidades logísticas sobre o ciclo de entrega de pedido, construído com base em Baron e Kenny (1986), é mostrado na Figura 1.

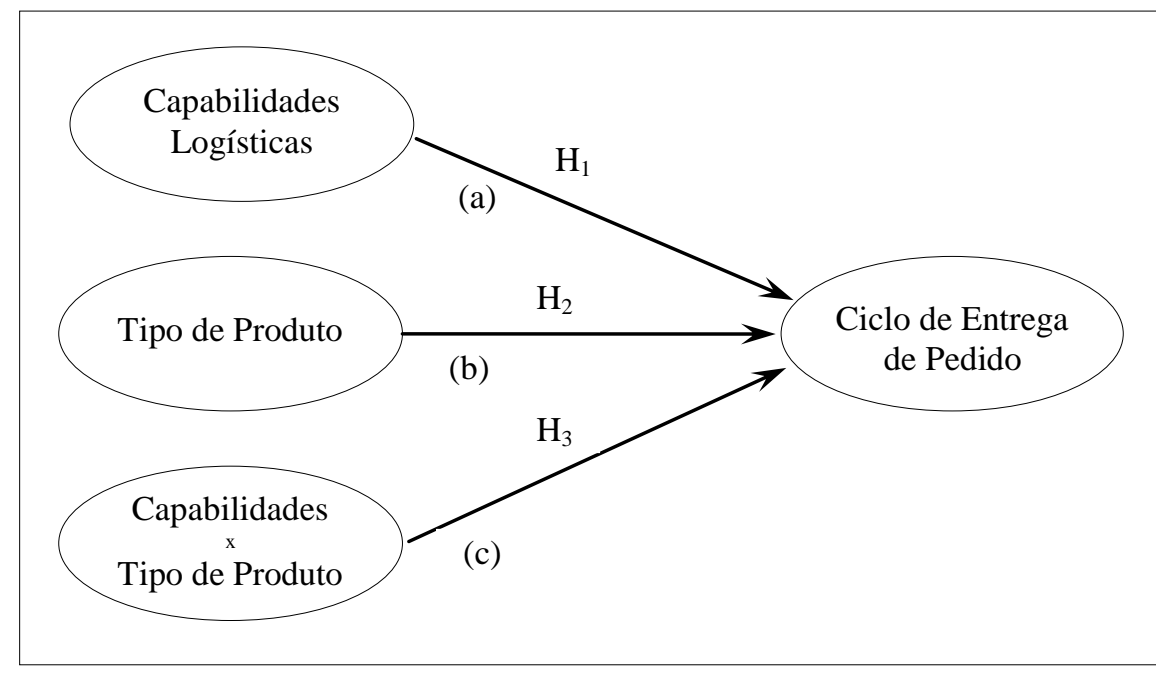

Figura 1 - Modelo da pesquisa Fonte: os autores

Como se pode notar na Figura 1, o modelo apresenta três caminhos que podem influenciar a eficiência do ciclo de entrega de pedido: a) as capabilidades logísticas como uma variável preditora (caminho a); b) o tipo de produto como variável moderadora (caminho b) e; c) a interação, ou, o produto da variável preditora com a moderadora (caminho c). A hipótese de moderador é suportada se a interação (caminho c) é significativo. Pode-se haver efeitos significativos para as variáveis preditora e moderadora (caminhos a e b) embora, estes efeitos 
O efeito do tipo de produto e das capabilidades logísticas sobre o ciclo do pedido

significativos, não sejam, conceitualmente, relevantes para testar a hipótese de variável moderador (BARON; KENNY, 1986).

O suporte teórico e hipóteses que sustentam o modelo são descritos a seguir.

\subsection{Capabilidades Logísticas e o Ciclo de Entrega de Pedido}

Capabilidade logística é um conceito emergente para criação de valor em diferentes disciplinas ou ênfases estratégicas (MORASH; DROGE; VICKERY, 1996; TEECE; PISANO; SHUEN, 1997). Utilizado na literatura de forma intercambiável com o termo “competências distintivas", "capabilidades" representam, segundo Lycnh, Keller e Ozment (2000), recursos envolvidos nas rotinas e práticas de uma organização que não podem ser comercializadas ou imitadas.

Em ambientes de mudanças rápidas, em que os produtos apresentam vida mais curta da que teriam em ambiente mais estável, as capabilidades para a logística internacional assumem papel estratégico por envolver atividades que contribuem para o gerenciamento dos quatro P's (produto, preço, promoção e praça) relacionados a Marketing (CHRISTOPHER, 1999; KOTLER, 2000). Aspectos como adicionar valor de informação à cadeia produtiva a fim de rastrear a movimentação de produtos da origem ao destino (NOVAES, 2007), estar preparado para as constantes mudanças de expectativas do cliente, e a transição de produtos de alto valor agregado para produtos commodities, têm impulsionado a logística a ampliar suas atividades para reduzir custos e viabilizar a competitividade dos produtos exportados brasileiros.

Atualmente, os gestores da logística têm diversas opções para melhorar seus sistemas, mas para isso é importante observar as melhores práticas da logística mundial (GOLDSBY; STANK, 2000; CLOSS; XU, 2000). Um estudo de destaque foi realizado em 1995 pelo Global Logistics Research Team na Michigan State University, que permitiu a elaboração de um modelo de competência de logística de classe mundial (CLM, 1995). O objetivo foi entender como as melhores empresas do mundo atingiam e mantinham sua excelência logística. Destacaram-se quatro capabilidades logísticas de classe mundial: a) Posicionamento e referiu-se à seleção de estratégias e estruturas para conduzir as operações; b) Integração e referiu-se a o que e como fazer para desenvolver operações logísticas de excelência; c) Agilidade e referiu-se à capacidade da empresa reagir às mudanças das necessidades dos clientes e; d) Mensuração e referiu-se a sistema estruturado de medição, interno e externo à empresa, de desempenho logístico.

A logística, para Christopher (1999), reflete uma preocupação com a necessidade de se obter uma vantagem competitiva em mercados que estão sujeitos a mudanças econômicas

REAd | Porto Alegre - Edição 80 - N 1 - janeiro/abril 2015 - p. 141-169 
rápidas e que somente serão premiadas as empresas que forem capazes de proporcionar valor adicionado em escalas de tempos cada vez menores.

Bae (2012) e Luo, Rosemberg e Barnes (2009) reforçam a importância da integração logística para criar valor para o cliente e a redução do tempo do ciclo de pedido é um elemento críticos da gestão logística. Nesse sentido, a empresa deve fornecer utilidade de tempo e de lugar na transferência de produto ou serviço entre o comprador e o vendedor (CHRISTOPHER, 1999).

Assim, a localização das instalações deve ser estabelecida, as informações obtidas devem ser compartilhadas, o transporte providenciado, o estoque posicionado e, quando necessário, devem ser realizadas atividades de armazenagem, manuseio de materiais e embalagens. $\mathrm{Na}$ visão de Brown et al. (2006), à medida que os setores tendem a se tornar concentrados, por meio das fusões e aquisições, para suportar os custos das operações globais, o alinhamento com o fornecedor certo se torna cada vez mais significativo, dado que a natureza das atividades envolvidas no ciclo de entrega de produto é propensa a considerável variância (BOWERSOX; CLOSS; COOPER, 2006).

Assim, é de se esperar:

$\mathrm{H}_{1}$ : Capabilidade logística influencia o ciclo de entrega de pedido

\subsection{Tipo de Produto e o Ciclo de Entrega de Pedido}

David e Stewart (2009) e Minervini (2001) mostraram que o processo logístico de exportação inclui as atividades de planejamento, implementação e controle do fluxo e da armazenagem de mercadorias, serviços e informações a elas relacionadas, partindo do ponto de origem ao ponto de consumo final da cadeia, localizado em outro país. A função principal da logística internacional é o movimento físico das mercadorias, identificando os fornecedores para a empresa e da empresa para os clientes finais (DORNIER et al., 2000). Por isso, algumas atividades são inerentes a este processo, tais como: negociação do pedido, liberação na alfândega, controle de documentos, escolha do transporte internacional, intermodal ou multimodal, números de intermediários envolvidos (bancos, seguradoras, receita federal, entidades reguladoras ou fiscalizadoras setoriais, despachantes, transportadores e armadores) e a definição da embalagem logística, de acordo com o roteiro determinado. 
O efeito do tipo de produto e das capabilidades logísticas sobre o ciclo do pedido

O ciclo de entrega de pedidos de produtos para exportação, segundo David e Stewart (2009), basicamente, pode ser representado por negociação de pedidos, transporte até o porto, despacho do produto e embarque do produto.

A negociação de pedidos ocorre entre empresa exportadora e importadora, cujas atividades envolvem a escolha dos INCOTERMS (International Comercial Terms) que satisfaçam a ambos (ICC, 2010; LUDOVICO, 2007). O transporte do produto, da origem ao destino, na condição de modal único, intermodal ou multimodal, pode reduzir o tempo de entrega do produto (COYLE; BARDI; LANGLEY, 2003). O despacho aduaneiro, relacionado ao cumprimento de normas e regulamentos oficiais de natureza administrativa têm aprimorado sistemas operacionais como o regime especial de exportação temporária (RFB, 2015a) e o despacho aduaneiro expresso, Linha Azul (RFB, 2015b) para agilizar o embarque dos produtos (SOSA, 1999; CARLUCCI, 1996).

Vencido o despacho aduaneiro, ocorre o embarque do produto. Os produtos exportados para países da América Latina, em geral, são realizados pelo modo rodoviário e ferroviário. Para países da América Central, do Norte, Europa, África e Ásia, os transportes são feitos pelos modais marítimos e aéreos.

Diante da amplitude do ciclo de entrega de produto, observa-se que quanto melhor a infraestrutura de portos, aeroportos, rodovias e ferrovias do país, maior é a facilidade para a comercialização e exportação dos produtos nacionais no mundo globalizado. Não obstante observa Fleury (2003), mesmo em sistemas de processamento de pedidos automatizados, a execução do ciclo de entrega de pedidos não é imune a problemas como percepções conflitantes entre cliente e fornecedores sobre o real desempenho do ciclo de entrega de pedido, ocorrência da variabilidade significativa nos tempos de respostas do ciclo e flutuações exageradas da demanda ao longo do tempo de resposta do ciclo.

Para Mentzer, Min e Bobitt (2004), o papel fundamental da logística é encurtar ciclos de entregas de pedidos por meio da coordenação da cadeia de suprimentos e capabilidades operacionais visando criar valor e satisfação ao cliente. Bowersox, Closs e Cooper (1999) e Zhao, Droge e Stank (2001), afirmam que a logística possui as capabilidades operacionais da gestão de informação para desenvolver sistemas, analisar, armazenar e até mesmo distribuir de forma tática as informações estratégicas, dentro e fora da empresa, que Gimenez e Ventura (2005) definem como integração interna, dentro das fronteiras da empresa, e como coordenação externa, a integração das atividades da logística além das fronteiras das empresas.

REAd | Porto Alegre - Edição 80 - N 1 - janeiro/abril 2015 - p. 141-169 
Acrescenta ainda, Paula (2007) e Cheung, Myers e Mentzer (2010), para melhorar os sistemas logísticos e ter um ciclo de entrega do pedido competitivo, é preciso investir na qualidade dos serviços de processamento logísticos, treinamento das pessoas envolvidas e promover inovações tecnológicas, dado que as vantagens competitivas são extremamente voláteis no tempo (CAMPANÁRIO; MUNIZ-DA-SILVA, 2004).

Assim, é de se esperar que:

$\mathrm{H}_{2}$ : Tipo de produto influencia o ciclo de entrega de pedido

\subsection{Interação entre Tipo de Produto e Capabilidade Logística}

A aceleração das cadeias globais de valor e a redução dos preços das tecnologias de processo e da informação, iniciadas na década de 1980, houve um fracionamento da produção em busca de facilidades de fabricação quer seja pela proximidade dos mercados, mão de obra de baixo custo, flexibilidade das normas ambientais, economias fiscais ou clusters tecnológicos de produção para obter vantagens competitivas (DUPAS, 2004). Face à fragmentação da produção, a logística, tem surgido como um elemento importante para mover e posicionar mercadorias para além dos limites das fronteiras das empresas (BOWERSOX; CLOSS; COOPER, 2006).

Exemplo disso pode ser visto nos alimentos, minérios e outras commodities. À medida que os sistemas logísticos são aperfeiçoados, o consumo e a produção podem empreender uma separação geográfica. Algumas regiões do globo terrestre podem se especializar nas commodities para cuja produção possuem condições mais favoráveis (Ballou, 2006). Os produtos necessários, mas escassos ou produção local inexistente podem ser, então, importados. Essas trocas de mercadorias seguem o princípio da vantagem comparativa e ajuda a explicar o alto nível de comércio internacional hoje existente (CHASE, JACOBS, AQUILANO, 2006). Basicamente, existem dois tipos de embarques:

a) carga em container. Segundo Ludovico (2007) com a necessidade de reduzir custos de transporte, manuseio, menor tempo de carregamento da carga nos modais utilizados, aumentar a segurança e rapidez nos intercâmbios comerciais, houve o surgimento de uma caixa padronizada, que foi denominada como container, tendo sido projetado para facilitar a carga e descarga dos navios, de forma rápida e eficiente. Devido ao fato de o container ser imune às intempéries do tempo, este equipamento proporciona uma redução com gastos de embalagem. 
O efeito do tipo de produto e das capabilidades logísticas sobre o ciclo do pedido

Deve-se salientar que este equipamento se tornou a espinha dorsal do transporte internacional, especialmente via modal marítimo.

Este modo é utilizado principalmente quando os produtos são de alto valor agregado. Isto não impede que carreguem mercadorias de baixo valor agregado, mas o espaço disponível para este tipo de mercadoria é bem limitado.

b) carga solta (ou breakbulk), a granel (bulk) ou líquida. Segundo Martins (2005) a carga breakbulk é um sistema convencional de transporte de carga geral, isto é, embarca-se e transporta-se a carga solta nos navios em volumes individuais. Exemplos: bobinas de papel, de aço, fardos de celulose, sacos de açúcar, etc. Quando uma carga é embarcada a granel ou bulk, pode ser sólida ou líquida. Estas duas formas de embarques são utilizadas quando ela não pode ser "conteineirizada". Devido ao baixo valor agregado destas mercadorias e o alto volume em um só embarque, os armadores de carga em contêineres têm pouco interesse por este tipo de carga.

Não obstante, pressões por redução de estoques e de custos vem induzindo clientes institucionais para compras mais frequentes e em menores quantidades, com exigência de prazos de entrega cada vez menores, livre de atrasos ou erros decorrentes da má conservação de estradas, deficiências no embarque e desembarque de mercadorias e congestionamentos nas regiões portuárias.

Estas pressões, conduz o exportador de produtos commodity ou industrializado, associados às capabilidades logísticas próprias ou de terceiros, escolher o melhor modo de transporte (rodoviário, marítimo, ferroviário ou por meio da intermodalidade) para o destino final das mercadorias no país estrangeiro e contribuir decisivamente para melhorar o padrão econômico da vida em geral.

Assim, é de esperar que:

$\mathrm{H}_{3}$ : A interação entre tipo de produto (commodity ou industrializado) e capabilidades logísticas influencia o ciclo de entrega de pedidos.

\section{PROCEDIMENTOS METODOLÓGICOS}

\subsection{Natureza e Tipo de Pesquisa, Instrumento de Coleta de Dados e Sujeito da Pesquisa}

Com o objetivo de entender, identificar e verificar a adequabilidade da utilização das medidas e escalas relacionadas às capabilidades logísticas (consideradas de classe mundial) 
constituída, originalmente, de 68 assertivas e desenvolvida pelo Council of Logistics Management (CLM, 1995) e utilizadas por autores como Goldsby e Stank (2000) e Closs e $\mathrm{Xu}$ (2000) e; construir e validar medidas e escalas relacionadas ao processo de ciclo de entrega de pedidos de produtos para exportação, com base em autores como David e Stewart (2009) e Dornier et al., (2000), realizou-se no primeiro semestre de 2010, uma pesquisa de natureza exploratória do tipo qualitativo, junto a sete gestores de empresas de segmentos econômicos de bens de capital, café, papel e celulose e suco de laranja. A razão da escolha destes segmentos econômicos se deu pela representatividade econômica na exportação dos produtos para diversos países além de serem participantes da cadeia global de valor.

A seguir, construiu-se a versão preliminar de um questionário, que submetido a prétestes, junto aos mesmos sete gestores, deu origem a um instrumento definitivo, basicamente, composto de quatro blocos. O primeiro e o segundo blocos referiram-se a dados dos respondentes e das empresas com seus aspectos logísticos. O terceiro bloco, composto de 53 assertivas, referiu-se às capabilidades logísticas, sendo 13 assertivas relacionadas ao Posicionamento Estratégico, 22 assertivas relacionadas à Integração Logística, 9 assertivas relacionadas à Agilidade de Entrega e 9 assertivas relacionadas às Medidas de Desempenho. Por último, o quarto bloco, composto de 28 assertivas, referiu-se ao processo do ciclo do tempo de entrega do pedido para exportação.

Definido o questionário, selecionou-se uma amostra de empresas exportadoras, extraídas do catálogo dos exportadores brasileiros da CNI (Confederação Nacional das Indústrias), para fazer parte do estudo. Em seguida, o questionário, cujas medidas e escalas são mostradas no Apêndice 1, foi enviado por e-mail para os gestores da área de exportação das empresas selecionadas, com um breve resumo sobre os objetivos da pesquisa.

\subsection{Tratamentos dos dados, Delimitação do Estudo e Limitação do Método}

Para tratar os dados coletados com o questionário utilizou-se: a) estatística descritiva para organizar, descrever e sumarizar dados; b) análise da correlação para obter o valor R e um nível de significância. $\mathrm{O}$ valor de $\mathrm{R}$ indica a magnitude do relacionamento e o nível de significância indica a semelhança que o relacionamento reportado é simplesmente devido às condições aleatórias. $\mathrm{O} \mathrm{R}^{2}$, estatisticamente, mede o poder de explicação do relacionamento; b) análise de regressão linear múltipla hierárquica (ABBAD; TORRES, 2002) para estimar modelo estatístico, mostrado na Figura 1, para prever os valores de uma variável dependente com base nos valores correspondentes de pelo menos uma variável explicativa ou independente e; c) análise de variância para dois fatores, two-way ANOVA (LEVINE et al., 
O efeito do tipo de produto e das capabilidades logísticas sobre o ciclo do pedido

2005), como contra prova à análise da regressão, para examinar, de modo mais claro, os efeitos (ou interações) entre os fatores (ou variáveis independentes categóricas).

$\mathrm{Na}$ delimitação do estudo foram consideradas: a) quanto ao escopo, a pesquisa ficou circunscrita às empresas exportadoras de bens de capital, papel, celulose, carne, soja, café e açúcar e; b) quanto à concepção, utilizou-se da perspectiva transversal.

Quanto à limitação do método, basicamente, se deram: a) pelo tamanho da amostra, que impossibilitou utilizar técnicas estatísticas mais robusta como a análise fatorial para validar as medidas e escalas. Neste caso, necessitaria de cinco a 10 respondentes para cada assertiva do modelo (HAIR et al., 2005). Além disso, houve um desbalanceamento quanto ao tipo de produto exportado. Do tal de 56 empresas, 14 corresponderam a produtos industrializados exportados por containers e, 42 a produto commodities exportados a granel. Ressalta-se no entanto, dada a natureza da pesquisa ser exploratória, esta limitação pode ser contornada e; b) pela escolha das empresas, que se deu por julgamento dos pesquisadores (MALHOTRA, 2001). Os pesquisadores, por meio de julgamentos ou experiências, escolheram as empresas do catálogo da CNI (Confederação Nacional das Indústrias) a serem incluídas na amostra, por considerarem representativas da população de interesse de estudo.

\section{ANÁLISES DOS DADOS E RESULTADOS}

Os dados foram coletados no primeiro semestre de 2011. Foram obtidos 56 questionários aptos a serem analisados que apresentaram as características a seguir descritas.

a) quanto aos aspectos dos respondentes e empresas:

1) em relação aos respondentes, $30,3 \%$ trabalhavam na área de vendas para o mercado externo, $62,5 \%$ na área de logística para o mercado externo e os restantes, 7,2\% trabalhavam em áreas diversas como comercial interno, operações e suprimentos. Quanto aos cargos, $73,2 \%$ dos respondentes eram gerentes e coordenadores. A maioria dos entrevistados $(54,9 \%)$ atuava na função de comércio exterior há mais de seis anos e estavam nas empresas há menos de cinco anos.

2) em relação às empresas, $26,8 \%$ era do setor de bens de capital, $17,9 \%$ era do setor de papel e celulose, $16,1 \%$ do setor de açúcar e os demais, eram constituídas de empresas do setor de carne, soja e café. Foram mencionados pelos respondentes que os principais países de exportação de produtos foram: Alemanha, China e Estados Unidos. Com menor porcentagem

REAd | Porto Alegre - Edição 80 - N 1 - janeiro/abril 2015 - p. 141-169 
foram citadas a Arábia Saudita, Austrália e Canadá. Quanto ao faturamento das empresas da amostra, 41,1\% foram consideradas de grande porte. Já no que se refere ao INCOTERMS, o CIF (Cost, Insurance and Freight) foi o mais utilizado, seguido do FOB (Free on Board) com $48,2 \%$ e $44,6 \%$, respectivamente.

\section{b) Estatística Descritiva}

A Tabela 1 apresenta a estatística descritiva para as assertivas das capabilidades logísticas e ciclo de entrega do pedido.

Tabela 1 - Resultados da Estatística Descritiva

\begin{tabular}{lccccccccc}
\hline \multicolumn{1}{c}{ ASSERTIVAS } & $\begin{array}{c}\text { N. de } \\
\text { Assertivas }\end{array}$ & Média & Mediana & $\begin{array}{c}\text { Desvio } \\
\text { Padrão }\end{array}$ & Min & Max & Sk & Ku & $\begin{array}{c}\boldsymbol{\alpha} \\
\text { Cronbach }\end{array}$ \\
\hline Posicionamento & 13 & 4,20 & 4,19 & 0,70 & 2,23 & 6,00 & $-0,222$ & 0,520 & 0,818 \\
Integração & 22 & 4,02 & 4,02 & 0,73 & 2,32 & 5,73 & $-0,113$ & $-0,196$ & 0,927 \\
Agilidade & 9 & 4,06 & 4,11 & 0,93 & 2,11 & 5,78 & $-0,009$ & $-0,776$ & 0,902 \\
Medidas Desempenho & 9 & 3,89 & 3,89 & 1,00 & 1,22 & 6,00 & $-0,482$ & 0,601 & 0,894 \\
Capabilidade Logística & 53 & 4,05 & 4,08 & 0,69 & 2,72 & 5,83 & $-0,068$ & $-0,385$ & 0,959 \\
Ciclo Entrega Pedido & 28 & 3,80 & 3,79 & 0,59 & 2,50 & 5,29 & 0,173 & $-0,094$ & 0,783 \\
\hline
\end{tabular}

Nota: Sk (Skweness) e Ku (Kurtose) tratam-se do perfil da distribuição de dados quando à Assimetria e Achatamento, respectivamente.

Fonte: Dados da pesquisa

Observou-se, pela Tabela 1, que as consistências internas, dada pelo coeficiente Alpha $(\alpha)$ de Cronbach, das capabilidades logísticas e ciclo de entrega de pedidos foram superiores a 0,7, atendendo assim, a recomendação de Hair et al. (2005), cujo limite mínimo para aceitabilidade é de 0,6, em pesquisas exploratórias. Este resultado mostrou a unidimensionalidade do uso de escala múltipla ou escala somada, denotando que tanto as assertivas das capabilidades com as assertivas do ciclo de entrega, estão fortemente associadas e representam um só conceito (HAIR et al., 2005).

O grau de discordância / concordância tenderam para o lado concordante da escala, cujo grau variou entre 3,80 e 4,20 para uma escala entre 1 e 6 . Além disso, nas distribuições dos dados, enquanto as capabilidades mostraram-se negativamente assimétrica e relativamente achatada, o ciclo de entrega mostrou-se positivamente assimétrica e relativamente achatada. Detalhes sobre a média aritmética, desvio padrão, assimetria (sk) e Kurtose (ku) para cada assertiva são mostradas no Apêndice 1.

c) Coeficientes de correlação $(\mathrm{R})$ e coeficientes de determinação $\left(\mathrm{R}^{2}\right)$ 
O efeito do tipo de produto e das capabilidades logísticas sobre o ciclo do pedido

Outro teste estatístico utilizado foi o coeficiente de correlação para determinar a magnitude do relacionamento entre duas variáveis, neste caso, as capabilidades logísticas e o ciclo de entrega de pedidos. O resultado da análise é mostrado na Tabela 2.

Tabela 2 - Resultados dos coeficientes de correlação $(\mathrm{R})$ e de determinação $\left(\mathrm{R}^{2}\right)$

\begin{tabular}{lcc}
\hline \multicolumn{1}{c}{ VARIÁVEIS } & $\begin{array}{c}\text { Coeficiente de Correlação } \\
(\mathbf{R})\end{array}$ & $\begin{array}{c}\text { Coeficiente de Determinação } \\
\left(\mathbf{R}^{\mathbf{2}}\right)\end{array}$ \\
\hline Posicionamento & $0,488^{* * *}$ & 0,238 \\
Integração & $0,496^{* *}$ & 0,246 \\
Agilidade & $0,406^{* *}$ & 0,165 \\
Medidas de Desempenho & $0,438^{* *}$ & 0,192 \\
Capabilidades Logísticas & $0,536^{* *}$ & 0,287 \\
Tipo de Produto & $-0,110$ & 0,012 \\
\hline \multicolumn{2}{c}{ Nota: ${ }^{* *}$ Indica o coeficiente de correlação de Pearson - Nível de Significância $(\alpha \leq 0,01)$}
\end{tabular}

Observaram-se, pela Tabela 2, evidências de que as capabilidades logísticas estavam correlacionadas com o ciclo de entrega dos pedidos em nível de significância estatística ( $\alpha \leq$ $0,01)$. Os coeficientes de correlação $(R)$ e o coeficiente de determinação $\left(R^{2}\right)$ indicaram que as capabilidades logísticas bem como seus elementos (posicionamento, integração, agilidade e medidas de desempenho) estavam associadas ao ciclo de entrega de pedidos. Todos os valores de $\mathrm{R}$ excederam 0,40 , com todos os coeficientes demonstrando significância estatística. $\mathrm{O} \mathrm{R}^{2}$ indicou que as capabilidades logísticas, individualmente, explicaram de 16,5\% (Agilidade) a 24,6\% (Integração) da variação das práticas do ciclo de entrega do pedido. As capabilidades logísticas totais explicaram $28,7 \%$ da variação. O nível de significância indicou menos de $1 \%$ de chance de que tais valores positivos poderiam ser observados se existissem sem o atual relacionamento.

Quanto ao tipo de produto, cujo valor do coeficiente de correlação foi de $-0,110$, não houve evidência de correlação significativa com o ciclo de entrega. Segundo Baron e Kenny (1986) é desejável que a variável moderadora (tipo de produto) seja não correlacionada nem com a variável preditora (capabilidade logística) nem com a variável dependente (ciclo de entrega) para se ter clareza da interação entre as variáveis preditora e moderadora. A correlação entre tipo de produto e ciclo de entrega, deste estudo específico, o valor foi de 0,272 significativo para $(\alpha \leq 0,05)$.

Em termos administrativos, a correlação resultante evidenciou que as capabilidades logísticas estavam relacionadas com práticas de processo de ciclo de entrega, mas a natureza 
do relacionamento, se causal ou aleatória, não pode ser determinada somente com a análise de correlação.

d) Regressão Linear Múltipla

Por conta disso, submeteu-se os dados a testes de regressão múltipla, o método moderado hierárquico, para determinar, com clareza, o relacionamento entre capabilidades logísticas, bem como de suas competências (dadas por posicionamento, integração, agilidade e medidas de desempenho), tipo de produto e a interação (tipo de produto x capabilidades) sobre o ciclo de entrega de pedido. Os estágios da aplicação do método moderado hierárquico são mostrados no Apêndice 2.

O resultado final é mostrado na Tabela 3.

Tabela 3 - Regressão Linear - Variável Dependente: Ciclo de Entrega de Pedido

\begin{tabular}{|c|c|c|c|c|}
\hline \multirow[b]{2}{*}{$\begin{array}{l}\text { Competências Logísticas } \\
\text { (Variáveis Independentes) }\end{array}$} & \multicolumn{4}{|c|}{ Estágio Final } \\
\hline & $\begin{array}{l}\text { Coefi- } \\
\text { ciente }\end{array}$ & $\begin{array}{c}\text { Valor } \\
\mathrm{t}\end{array}$ & $\begin{array}{l}\text { Tole- } \\
\text { rância }\end{array}$ & VIF \\
\hline Intercepto (Constante) & & n.s & & \\
\hline Posicionamento & & n.s & & \\
\hline Integração & & n.s & & \\
\hline Agilidade & & n.s & & \\
\hline Medidas de Desempenho & & n.s & & \\
\hline Capabilidades Logísticas & 0,45 & $4,66^{* *}$ & 1,00 & 1,00 \\
\hline Tipo de Produto & & n.s & & \\
\hline Interação: Tipo de Produto x Capabilidades & & n.s & & \\
\hline Estimativa F & $21,75^{* *}$ & & & \\
\hline $\mathrm{R}^{2}$ Múltiplo & 0,29 & & & \\
\hline $\mathrm{R}_{\text {ajustado }}^{2}$ & 0,27 & & & \\
\hline
\end{tabular}

Nota: ${ }^{* *}$ indica que o coeficiente de regressão foi significante para $(\alpha \leq 0,01)$ e, n.s. indica que o coeficiente de regressão foi não significante para $(\alpha \leq 0,05)$

Fonte: Dados da pesquisa

A análise da regressão linear múltipla, mostrada na Tabela 3 , evidenciou-se que as capabilidades logísticas, consideradas como a soma das competências logísticas dados por posicionamento, integração, agilidade e medidas de desempenho, influenciou positivamente no ciclo de entrega de pedido, suportando assim, a hipótese $\mathrm{H}_{1}$. Acrescentou-se ainda, que o resultado obtido não teve o efeito da multicolinearidade, como mostraram os valores da Tolerância e VIF (Variance Inflation Factor) que ficaram dentro dos valores de referências recomendados que são: acima de 0,10 e abaixo de 10, respectivamente (HAIR et al., 2005). 
O efeito do tipo de produto e das capabilidades logísticas sobre o ciclo do pedido

Ressalta-se, que as competências logísticas (posicionamento, integração, agilidade e medidas de desempenho), tipo de produto e a interação (tipo de produto e capabilidades) foram excluídas do modelo.

d) O Efeito da Interação entre Tipo de Produto e Capabilidades sobre o Ciclo de Entrega

Para examinar o efeito da interação entre tipo de produto e capabilidades logísticas sobre o ciclo de entrega de pedido, utilizou-se da técnica da análise de variância de dois fatores (two-way ANOVA). A vantagem do uso da técnica da análise de variância de dois fatores é que ela permite examinar, com mais clareza, as interações entre os fatores.

Os resultados dos efeitos de interação das capabilidades logísticas e do tipo de produto nos resultados do ciclo de pedido são mostrados na Tabela 4.

Tabela 4 - Teste ANOVA para dois fatores: Capabilidades Logísticas e Tipo de Produto

\begin{tabular}{|c|c|c|c|c|c|c|}
\hline Variáveis & $\begin{array}{l}\text { Graus } \\
\text { Liber } \\
\text { dade }\end{array}$ & $\begin{array}{l}\text { Sequência } \\
\text { Soma dos } \\
\text { Quadrados }\end{array}$ & $\begin{array}{c}\text { Ajustado } \\
\text { Soma dos } \\
\text { Quadrados }\end{array}$ & $\begin{array}{c}\text { Ajustado } \\
\text { Quadrado } \\
\text { Médio }\end{array}$ & $\begin{array}{l}\text { Teste } \\
\text { F }_{\text {Calc }}\end{array}$ & $\begin{array}{l}\text { Signifi } \\
\text { cância }\end{array}$ \\
\hline (B) Tipo Produto: (Commodity/Industrializado) & 1 & 0,2310 & 0,0295 & 0,0295 & 0,12 & 0,733 \\
\hline (A) Capabilidades Logísticas (Grau) & 2 & 5,9714 & 3,3788 & 1,6894 & 6,71 & 0,003 \\
\hline Interação (Tipo de Produto* Capabilidades) & 2 & 0,1416 & 0,1416 & 0,0708 & 0,28 & 0,756 \\
\hline Resíduo & 50 & 12,5861 & 12,5861 & 0,2517 & & \\
\hline TOTAL & 55 & 18,9301 & & & & \\
\hline
\end{tabular}

Fonte: Dados da pesquisa

O resultado do teste de ANOVA com dois fatores (tipo de produto e capabilidades), em nível de significância estatística de $(\alpha \leq 0,05)$ e graus de liberdade, revelou que apenas a variável capabilidade logística teve influência na eficiência do ciclo de entrega de pedidos como é mostrado na Tabela 5.

Tabela 5 - Testes das Hipóteses

\begin{tabular}{|c|c|c|c|c|c|c|}
\hline \multirow{3}{*}{ Variáveis } & \multicolumn{4}{|c|}{ Estatística F } & \multirow{3}{*}{ Hipótese } & \multirow{3}{*}{ Decisão } \\
\hline & \multicolumn{3}{|c|}{ Estimado $(\alpha \leq 0,05)$} & \multirow{2}{*}{$\begin{array}{c}\text { Calcu- } \\
\text { lado }\end{array}$} & & \\
\hline & g.l. (numerador) & g.l. (denominador) & Valor & & & \\
\hline Capabilidades (A) & 2 & 50 & 3,19 & 6,71 & $\mathrm{H}_{1}$ & Suporta \\
\hline Tipo Produto (B) & 1 & 50 & 4,04 & 0,12 & $\mathrm{H}_{2}$ & Não Suporta \\
\hline Interação: (A) x (B) & 2 & 50 & 3,19 & 0,28 & $\mathrm{H}_{3}$ & Não Suporta \\
\hline
\end{tabular}


Portanto, com a evidência da não significância estatística da interação: tipo de produto e capabilidades logísticas, o tipo de produto não pode ser variável moderadora, conforme considerado no modelo mostrado na Figura 1, além da não evidência, da sua influência na eficiência do ciclo de entrega.

Após ter realizado os testes de significância para os fatores tipo de produto e capabilidades logísticas e a interação entre ambos os fatores, procurou-se construir um gráfico para melhor compreender e interpretar o resultado. Assim, o tipo de produto exportado, como base na coleta direta junto aos respondentes, foi classificado em dois grupos: o grupo $\mathrm{T}_{1} \mathrm{em}$ Commodities e o grupo $\mathrm{T}_{2}$ em Industrializados. Para as capabilidades logísticas, o grau de discordância / concordância, foram classificados em ordem crescente e associados a três grupos equitativos de empresas sendo: o grupo $\mathrm{C}_{1}$, de baixa capabilidade logística composta de 18 empresas e valor $1,00 \leq$ Capabilidade $\leq 3,72$; o grupo $C_{2}$, de média capabilidade logística composta de 19 empresas e valor $3,73 \leq$ Capabilidade $\leq 4,38$ e; o grupo $\mathrm{C}_{3}$, de alta capabilidade logística composta de 19 empresas e valor 4,39 $\leq$ Capabilidade $\leq 6,00$.

Na Tabela 6, é mostrada uma matriz de dupla entrada em que são observadas, nas linhas horizontais o fator capabilidade, nas linhas verticais o fator tipo de produto, e na intersecção o grau de discordância e concordância em termos de média aritmética e escala somada do ciclo de entrega de pedido.

Tabela 6 - Classificação das capabilidades logísticas e tipos de produtos

\begin{tabular}{|c|c|c|c|c|c|}
\hline & \multirow[b]{2}{*}{ CLASSIFICAÇÃO } & \multirow[b]{2}{*}{ Itens } & \multicolumn{3}{|c|}{ FATOR B (Tipo de Produto) } \\
\hline & & & $\begin{array}{l}\text { Commodity } \\
\left(\mathrm{T}_{1}\right)\end{array}$ & $\begin{array}{c}\text { Industrializado } \\
\left(\mathrm{T}_{2}\right) \\
\end{array}$ & $\begin{array}{l}\text { Diferença } \\
\left(T_{1}\right)-\left(T_{2}\right) \\
\end{array}$ \\
\hline \multirow{12}{*}{ 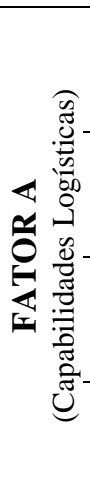 } & \multirow{3}{*}{$\begin{array}{c}\left(\mathrm{C}_{1}\right)-\text { BAIXA } \\
2,72 \geq \text { Capabilidade } \geq 3,72\end{array}$} & $\mathrm{n}$ & 10 & 8 & +2 \\
\hline & & Média Aritmética ${ }^{1}$ & 3,28 & 3,49 & $-0,21$ \\
\hline & & Escala Somada $^{2}$ & 91,90 & 97,75 & $-5,85$ \\
\hline & \multirow{3}{*}{$\begin{array}{c}\left(\mathrm{C}_{2}\right)-\text { MÉDIA } \\
3,79 \geq \text { Capabilidade } \geq 4,38\end{array}$} & $\mathrm{n}$ & 15 & 4 & +11 \\
\hline & & Média Aritmética ${ }^{1}$ & 3,80 & 3,89 & $-0,09$ \\
\hline & & Escala Somada $^{2}$ & 106,33 & 109,00 & $-2,67$ \\
\hline & \multirow{3}{*}{$\begin{aligned} & \left(\mathrm{C}_{3}\right)-\text { ALTA } \\
4,40 \geq & \text { Capabilidade } \geq 5,83\end{aligned}$} & $\mathrm{n}$ & 17 & 2 & +15 \\
\hline & & Média Aritmética ${ }^{1}$ & 4,20 & 4,07 & $+0,13$ \\
\hline & & Escala Somada $^{2}$ & 117,53 & 114,00 & $+3,53$ \\
\hline & \multirow{3}{*}{ Totais } & $\mathrm{n}$ & 42 & 14 & +28 \\
\hline & & Média Aritmética $^{1}$ & 3,84 & 3,69 & $+0,15$ \\
\hline & & Escala Somada $^{2}$ & 315,76 & 320,75 & $-4,99$ \\
\hline
\end{tabular}

Notas: ${ }^{1}$ Referiu-se média aritmética do grau de discordância / concordância (Discordo Totalmente $=1$ e Concordo Totalmente $=6$ ) atribuídas pelos respondentes às assertivas que compuseram o constructo ciclo de entrega de pedido em seu respectivo tipo de produto e capabilidade logística; ${ }^{2}$ Referiu à soma do grau de discordância / concordância (Discordo Totalmente $=1$ e Concordo Totalmente $=6$ ) atribuídas pelos respondentes às assertivas que compuseram o constructo ciclo de entrega de pedido em seu respectivo tipo de produto e capabilidade logística.

Fonte: Dados da pesquisa 
O efeito do tipo de produto e das capabilidades logísticas sobre o ciclo do pedido

Na Tabela 6 observaram-se, para ambos os tipos de produtos, à medida que as capabilidades aumentaram, o ciclo de entrega do pedido tornou-se mais eficiente, isto é, apresentou maior valor no lado concordante da escala.

Por meio de um gráfico, mostrado na Figura 2, foi possível ter maior clareza do comportamento das interações dos fatores. Enquanto o produto industrializado apresentou maior eficiência no ciclo de entrega até o ponto pouco acima da média das capabilidade, o produto commodity teve maior eficiência do ciclo de entrega de alta capabilidade.

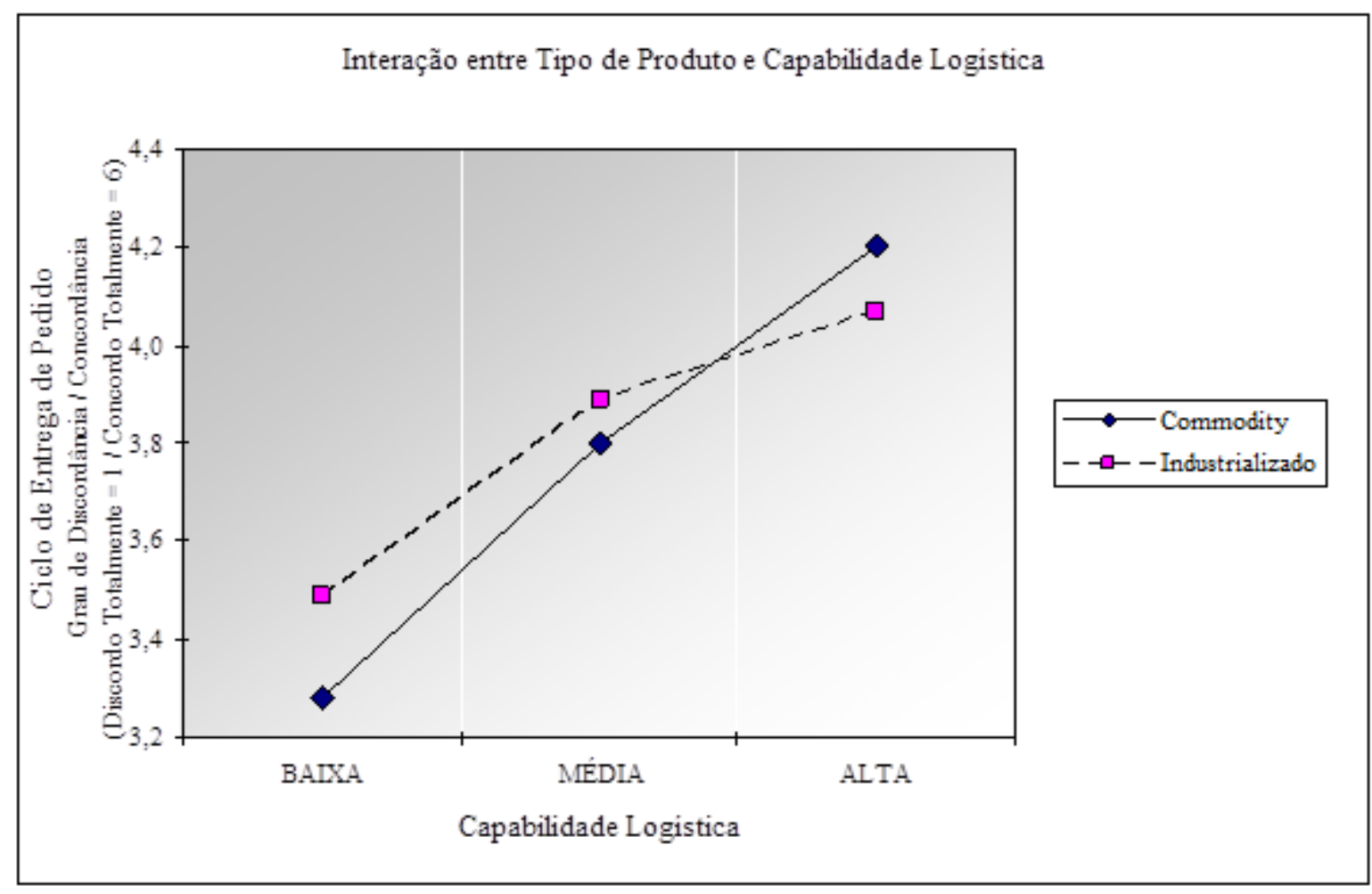

Figura 2 - Médias aritméticas de grau de discordância / concordância para o ciclo de entrega de pedido com base em tipo de produto e capabilidades logísticas

Fonte: Elaborado pelos autores

Todavia, as interações verificadas visualmente no gráfico, não foram representativas em nível de significância estatística $(\alpha \leq 0,05)$. Colocando de outro modo, não existiu evidências de interação entre esses dois fatores (tipo de produto e capabilidade), mostrado na Tabela 4, dado que o $\mathrm{F}_{\text {Calc }}($ igual a 0,28$)$ foi menor que o $\mathrm{F}_{\text {Estimado }}(\mathrm{em} \mathrm{3,19)}$.

Conforme se observou pela Figura 2, visualmente, existiu a interação, dado que as linhas representativas dos tipos de produtos, elas, se cruzaram. Não obstante, o teste da estatística F indicou a não significância estatística em nível de 5\%. Nesse sentido Calegare (2005) argumenta que a interação pode existir mesmo quando ela não for considerada significativa no 
teste da estatística F. Isto pode ocorrer, por exemplo, quando o erro residual é muito grande, reduzindo a estatística $\mathrm{F}_{\text {calc }}$, ou quando o número de réplicas é pequeno e insuficiente para detectar essa interação.

\section{CONSIDERAÇÕES FINAIS}

Este estudo procurou evidencias empíricas da influência da interação do tipo de produto e capabilidade logística na eficiência do ciclo de entrega de pedido. O resultado revelou que apenas a capabilidade logística influenciou na eficiência do ciclo de entrega. Todavia, este resultado possibilitou análises de implicações de natureza teórico-empírica, conforme são apresentadas a seguir.

1) Em relação aos aspectos teóricos, a primeira implicação foi a constatação da importância das capabilidades logísticas para fornecer serviços de qualidade com ciclo de entrega de pedido otimizado. Trabalho similar como de Souza Junior et al. (2013), em quatro empresas de bebidas do Estado de Amazonas, os resultados evidenciaram que apenas uma das empresas possuía aderência ao modelo de classe mundial em logística. Outro trabalho apresentado por Mollenkopf e Dapiran (2005), em empresas Australianas e Nova Zelandesas, verificou-se que a maioria das empresas tinham seus esforços focado para a integração da logística interna, comparado com os objetivos de integração externa. Outro relato interessante é o de Tamer (2006), segundo o qual, no Brasil, para um produto ser exportado leva, em média, 39 dias para chegar ao porto e ser embarcado, enquanto nos Estados Unidos a média é de 12 dias e na Dinamarca é de 5 dias. A caminhada para aprofundamento no campo do conhecimento da logística pode envolver a maneira como outros países atentam para as capabilidades logísticas. Por exemplo, no Brasil o estudo da logística tem como base os modais de transportes (rodoviário, aéreo, ferroviário, marítimo, fluvial e dutoviário). No Japão, segundo Horn e Toshinori (2005), a logística é vista como um sistema que se desdobra em três segmentos: logística urbana (city logistic), logística regional e logística internacional. Em países da Europa Ocidental como o programa Marco Polo (EU, 2012), enfatiza a redução dos congestionamentos nas auto-estradas e os problemas ambientais para aumentar a eficiência do tráfego e desempenho (operacional e financeiro), por meio da coordenação dos modos de transportes. Nos Estados Unidos, a ênfase das políticas logísticas está nos sistemas intermodais que consiste em intercambiar mercadorias, de diferentes partes do NAFTA 
O efeito do tipo de produto e das capabilidades logísticas sobre o ciclo do pedido

(North America Free Trade Agreement), para diferentes modos de transportes (HORN; TOSHINORI, 2005).

2) Em relação aos aspectos empíricos: a) para os produtos commodities como soja e café, que em geral são transportados a granel, há maior dificuldade para o acesso e escoamento dos produtos nos portos, além de maiores custos diários nos transportes e demurrage de navios. Sistemas de armazenagens para resguardar a qualidade do produto e de transportes para obter eficiência na movimentação das cargas ainda são precários na infraestrutura logística brasileira; b) para os produtos industrializados, como máquinas e equipamentos ou outros produtos de alto valor agregado (ou produtos industrializados), em geral transportados em contêineres, há vantagens em relação às movimentações de cargas a granel como maior proteção da carga, segurança, redução de custos no embarque e desembarque e facilidade de movimentação.

No entanto, tanto para a exportação de produtos commodities como de produtos industrializados, não há evidências de influência do tipo de produto exportado e as capabilidades logísticas sobre o ciclo de entrega do pedido Isto leva, em acordo com a hipótese formulada, a existência de fatores externos agindo para neutralizar os esforços na busca da eficiência logística, tais como deficiências em infraestrutura logística relacionadas a portos, rodovias, armazéns e terminais de transbordos.

Em termos de práticas logísticas, independentemente, do tipo do produto exportado, a empresa deve introduzir adaptações para manter a competitividade como embalagens especiais, desembaraço alfandegário, necessidades de estoques maiores, quantidade de documentos para a operação e sistema de informação internacional (BOWERSOX; CLOSS, 2001).

Por fim, esta pesquisa serviu como uma proposta de analisar empiricamente a influência do tipo do produto e capabilidades logísticas sobre o ciclo de pedido. Não obstante, muitas questões permanecem sem respostas e que requerem substancialmente de mais investigação. Atualmente, as pesquisas logísticas são de grande importância para a redução do ciclo de pedidos, por meio, da melhoria dos serviços prestados, imagem da empresa e pode impactar grandes benefícios para a empresa. Nesse sentido, pesquisas futuras deveriam também determinar o efeito do tipo de produto e das capabilidades logísticas sobre a taxa de retorno dos investimentos, obsolescência dos estoques e satisfação do cliente. 


\section{REFERÊNCIAS}

ABBAD, G.; TORRES, C. V. Regressão múltipla stepwise e hierárquica em Psicologia Organizacional: aplicações, problemas e soluções. Brasilia: Estudos de Psicologia, 7 (Número Especial), 19-29, 2002.

BAE, $\mathrm{H}$. The influencing factors of logistics integration and customer service performance for value creation of port logistics firms. The Asian Journal of Shipping and Logistics, v. 28, n. 3, pp. 345-368, 2012.

BARON, R. M.; KENNY, D. A. The moderator-mediator variable distinction in social psychological research: Conceptual, strategic, and statistical considerations. USA: Journal of Personality and Social Psychology, v. 51, pp. 1173-1182, 1986

BALLOU, R. H. Gerenciamento da cadeia de suprimentos/logística empresarial. Porto Alegre: Bookman, 2006.

BOWERSOX, D. J.; CLOSS, D. J. Logística empresarial, São Paulo: Editora Atlas, 2001.

BOWERSOX, D. J.; CLOSS, D. J.; COOPER, M. B. Gestão logística de cadeias de suprimentos. Porto Alegre: Bookman, 2006.

BOWERSOX, D. J.; ClOSS, D. J.; STANK, T. P. $21^{\text {st }}$ Century Logistics: Making Supply Chain Process. USA: Macgraw-Hill Series in Marketing, MacGraw-Hill, New York, NY. 1999.

BROWN, S.; LAMMING, R.; BESSANT, J.; JONES, P. Administração da Produção e Operações. Rio de Janeiro: Editora Campus / Elsevier, 373p, 2006.

CALEGARE, A. J. A. Introdução ao delineamento de experimentos. São Paulo: Editora Blucher, 2 ${ }^{a}$ Edição, 2005.

CAMPANÁRIO, M. A.; MUNIZ-DA-SILVA, M. 2004. Fundamentos de uma nova política industrial. São Paulo: Publifolha - Divisão de Publicações da Empresa Folha da Manhã S.A., Política Industrial 1, pp. 13-40.

CARLUCCI, J. L. Uma introdução ao sistema aduaneiro. São Paulo: Aduaneiras, 1996. 
CHEUNG, M. S.; MYERS, M. B.; MENTZER, J. T. Does relationship learning lead to relationship value? A cross-national supply chain investigation. Journal of operations management, v. 28, n. 6, 472-487, 2010.

CHASE, R. B; JACOBS, F. R.; AQUILANO, N. J. Administração da Produção para a Vantagem Competitiva. Porto Alegre: Bookman, 2006.

CHRISTOPHER, M. O marketing da logística: otimizando processos para aproximar fornecedores e clients. São Paulo: Futura, 1999.

CLM - Council of Logistics Management. World Class Logistics: the challenge of managing continuous change. United States of America: Oak Brook, 1995.

CLOSS, D. J.; XU, K. Logistics information technology practice in manufacturing and merchandising firms: an international benchmarking study versus world-class logistics firms. USA: International journal of physical distribution \& logistics management, v. 30, n. 10, pp. 869-886, 2000.

COYLE, J. J.; BARDI, E. J.; LANGLEY, C. J. The management of business logistics: a supply chain perspective. $7^{\mathrm{a}}$ ed. Mason, $\mathrm{OH}$ :South-western, 2003.

DAVID, P. A.; STEWART, R. D. Logística internacional. São Paulo: Cengage Learning, 2009.

DORNIER, P.; ERNST, R.; FENDER, M.; KOUVELIS, P. Logística e Operações Globais, Textos e Casos. São Paulo: Editora Atlas, 2000.

DUPAS, G. O impasse do valor adicionado local e as políticas de desenvolvimento. São Paulo: Publifolhas, 2004.

EU. European Union. Marco Polo: New ways to a green horizon. http://ec.europa.eu/transport/marcopolo/. Acessado em 21 de abril de 2012.

FISHER, Marshall, L. What is the Right Supply Chain for your Product? USA: Harvard Business Review. Reprint number 97205, pp. 105 - 116, March-April 1997.

FLEURY, P. F. O Sistema de processamento de pedidos e a gestão do ciclo do pedido. São Paulo: Atlas. In Logística e gerenciamento da cadeia de suprimentos: planejamento do fluxo de produtos e dos recursos. Coleção COPPEAD-UFRJ, pp. 452-455, 2003. 
A Infraestrutura e os desafios logísticos das exportações brasileiras.

Acessado em 6 de janeiro de 2015 de: http://www.luxafit.com.br/pv_art026.htm\#.VKx1cyvFzo. s.d.

FUGATE B. S; MENTZER, J. T; STANK, T. P. Logistics performance: efficiency, effectiveness, and differentiation. USA: Journal of Business Logistics. v. 31, n. 1; pp. 43 - 63, 2010.

GIMENEZ, C.; VENTURA, E. Logistics-production, Logistics-Marketing and External Integration. Their impact on Performance. USA: International Journal of Operations \& Production Management. v. 25, n. 1, pp.20-38, 2005.

GOLDSBY, T. J.; STANK, T. P. World class logistics performance and environmental responsible logistics practice. Journal of Business Logistics, 21(2), 187-208, 2000.

HAFFNER, R.; LINTHICUM, L.; PUNCHARD, B. Dando sentido aos produtos sensíveis. São Paulo: Inline Magazine. http://www.sidel.pt/sobre-nos/inline-magazine/making-sense-ofsensitive-products. Acesso em 6 de janeiro de 2014.

HAIR, Jr., J. F.; ANDERSON, R. E.; TATHAM, R. L.; BLACK, W. C. Fundamentos de métodos de pesquisa em administração. Porto Alegre: Bookman, 2005.

HORN, B. E.; TOSHINORI, N. Intermodal logistics policies in the EU, the US and Japan. Japan: Transport policy studie's review. v. 7, n. 4, pp. 2-14, 2005.

ICC - International Chamber of Commerce. Incoterms 2010. ICC official rules for the interpretation of trade terms. Paris: ICC Services Publication, 2010

KOTLER, P. Administração de marketing. São Paulo: Prentice Hall, 10ª edição, 2000.

LAMMING, R.; JOHNSEN, T.; ZHENG, Z.; HARLAND, C. An initial classification of supply networks. UK: International joumal of operations \& production management, v. 20, $\mathrm{n}$. 6, pp. 675-691, 2000.

LEVINE, D. M.; STEPHAN, D.; KREHBIEL, T. C.; BERENSON, M. L. Estatística, teoria e aplicações usando o Microsoft Excel em português. $3^{\text {a }}$ Edição, Rio de Janeiro: LTC, Edição, 819p, 2005.

LUDOVICO, N. Logística internacional: um enfoque em comércio exterior. São Paulo: Saraiva, 2007.

REAd | Porto Alegre - Edição 80 - N 1 - janeiro/abril 2015 - p. 141-169 
O efeito do tipo de produto e das capabilidades logísticas sobre o ciclo do pedido

LUO, X.; WU, C.; ROSENBERG, D.; BARNES, D. Supplier selection in agile supply chains: an information-processing model and illustration. USA: Journal of purchasing \& supply management, 15(4), 249-262, 2009.

LYNCH, D. F.; KELLER, S. B.; OZMENT, J. The effects of logistics capabilities and strategy on firm performance. USA: Journal of business logistics. v. 21, n. 2, pp. 47-67, 2000.

MALHOTRA, N. K. Pesquisa de marketing. Uma orientação aplicada. Porto Alegre; Editora Bookman, 3ª Edição, 719p. 2001.

MARTINS, A. C. Dicionário Comercial Marítimo (Dictionary of Shipping Terms). Paranaguá: ACM Publicações Ltda. Paranaguá, PR, Brasil - $4^{\mathrm{a}}$ edição ampliada, 2005.

MENTZER, J. T.; MIN, S.; BOBITT, L. M. Toward a unified theory of logistics. USA: International Journal of Physical Distribution \& Logistics Management. v. 34, n. 8, pp. 606627, 2004.

MDIC (Ministério do Desenvolvimento, Indústria e Comércio Exterior). Exportações brasileiras em 2013 têm terceiro melhor resultado da história. 2 de janeiro de 2014. Acessado em 6 de janeiro de 2015 de: http://www.desenvolvimento.gov.br/sitio/interna/noticia.php?area=5\&noticia=12923

MINERVINI, N. O exportador. São Paulo: Makron Books, 3ª Ed., 2001.

MOLLENKOPF, D.; DAPIRAN, G. P. World-class logistics: Australia and New Zealand. USA: International Journal of Physical Distribution \& Logistics Management. v. 35, Issue 1, pp. 63-74, 12p. 2005

MONTEIRO, R. Proposta de um modelo de apoio à tomada de decisão baseado em fatores críticos de sucesso. Tese de doutorado. Faculdade de Engenharia Mecânica da UNICAMP, Campinas, São Paulo, 2002.

MORASH, E. A.; DROGE, C. L. M.; VICKERY, S. K. Strategic logistics capabilities for competitive advantage and firm success. USA: Journal of business logistics. v. 17, n. 1, 1996.

NEDER, V. Ferrovia investe para melhorar eficiência. São Paulo: OESP. Caderno de economia, p. B3, 26 de dezembro de 2013.

NOVAES, A. G. Logística e Gerenciamento da Cadeia de Distribuição. Rio de Janeiro: Editora Campus, $3^{\text {a }}$ edição, 2007. 
PAULA, R. G. Logística internacional. Material de disciplina na modalidade à distância. 2a. ed. rev. e amp. Santa Catarina: Editora Palhoça, Unisul Virtual, 2007. Disponível no endereço http://busca.unisul.br/pdf/88813_Paulo.pdf. Acesso em 25 de fevereiro de 2013.

RFB - Receita Federal do Brasil. Regime Especial de Exportação Temporária. Acessado em 7 de janeiro de 2015 de: http://www.receita.fazenda.gov.br/Aduana/RegAdmExportTemp/RegExp/RegEspExpTemp.htm. 2015a

LINHA AZUL - Despacho Aduaneiro Expresso. Acessado em 7 de janeiro de 2015 de http://www.receita.fazenda.gov.br/aduana/linhaazul/OrientGerais.htm. 2015b

ROCHA, A.; FERREIRA-DA-SILVA, J. Transporte marítimo na exportação. São Paulo: SEBRAE Nacional. http://www.sebrae.com.br/customizado/negocios-internacionais/exportare-importar/comercio-exterior-1/logistica/174-46o-transporte-maritimo-naexportacao/BIA_17446. Acesso em 10 de janeiro de 2014.

SOSA, R. G. Temas aduaneiros: estudos sobre problemas aduaneiros contemporâneos. São Paulo: Aduaneiras, 1999.

SOUZA JUNIOR, A. A.; NOGUEIRA, R. J. C.; MELO, D. R. A.; SOARES FILHO, A. A. F.; SOARES, L. A. C. F. A utilização do world class logistics na mensuração do desempenho no processo de distribuição física de produtos no segmento de bebidas da cidade de Manaus. Rio de Janeiro: Sistemas \& Gestão - Revista Eletrônica. v. 8, pp. 302-316.

STOCK, G. N.; GREIS, N. P.; KASARDA, J. D. Enterprise logistics and supply chain structure: the role of fit. USA: Journal of operations management. v. 18, pp. 531-547, 2000.

TAMER, A. Brasil leva 39 dias para exportar. O Estado de São Paulo, caderno de economia, 2006.

TEECE, D. J.; PISANO, G.; SHUEN, A. Dynamic Capabilities and Strategic Management. USA: Strategic Management Journal, v. 18, n. 7, pp. 509-533, 1997

ZHAO, M.; DROGE, C.; STANK, T. P. The effects of logistics capabilities on firm performance: customer-focused versus information-focused capabilities. USA: Journal of Business Logistics. v. 22, pp. 91-107, 2001. 


\section{APÊEDICE 1: Medidas e Escalas}

Todas as assertivas foram medidas pela escala de Discordância / Concordância com seis graus de importância que variava de Discordo Totalmente $(\mathrm{DT}=1)$ a Concordo Totalmente $(\mathrm{CT}=$ 6). A média aritmética, desvio padrão, assimetria e curtose são mostradas para cada assertiva [média], [desvio padrão], [assimetria], [curtose].

\section{POSICIONAMENTO: $\alpha$-Cronbach $-0,818$}

1 A minha empresa planeja com antecedência diferentes tipos de serviços logísticos para atender à diversidade de clientes no mercado externo. [4,70], [1,11], [-0,849], [1,096]

2 A minha empresa analisa e implementa possíveis recomendações advindas do depto de logística como uma das bases de segmentação de clientes. [4,41], [1,23], [-0,723], [0,035]

A estratégia de minha empresa tem sido substituída de gerenciamento de funções para gerenciamento de processos. [4,14], [1,30], [-0,894], [0,571]

4 Minha empresa acredita que a direção estratégica, regras e o bom desempenho do supply chain de seus parceiros são fatores críticos para a obtenção de sucesso. [4,91], [1,10], [-0,923], [0,216]

5 Minha empresa segue e compartilha de forma clara e constante seus objetivos e expectativas comuns com os seus parceiros dentro da cadeia de suprimentos. [4,57], [1,04], [-0,547], [-0,177]

6 Em minha empresa a melhora nos indicadores de desempenho é obtida através da integração de operações com os parceiros dentro da cadeia de suprimentos. [4,27], [1,28], [-0,737], [0,391]

Minha empresa utiliza com sucesso soluções logísticas para mercadorias destinadas ao mercado

7 internacional baseadas em tempo, reposicionamento contínuo, resposta rápida e Just-in-Time com clientes e ou fornecedores. [4,21], [1,40], [-0,481], [-0,641]

Minha empresa tem conseguido reduzir o ciclo de vida do processo de seus clientes para o mercado externo nos últimos 3 anos. [4,21], [1,16], [-0,657], [0,034]

Minha empresa tem empregado o relacionamento logístico como uma combinação de distribuição de

9 facilidades, cross-dock, e em especial operações de entregas que são capazes de atender a todas solicitações dos clientes. [4,02], [1,10], [-0,794], [0,588]

10 Minha empresa utiliza a rotatividade das funções nos times de trabalhos para uma melhor obtenção de competências entre os funcionários. [3,18], [1,36], [0,245], [-0,629]

11 A média gerencia de minha empresa tem poder de decisão para todos os problemas de seu departamento. [4,30], [1,22], [-0,926], [0,286]

12 Minha empresa tem reduzido a estrutura formal da organização para uma estrutura totalmente integrada em operações. [4,14], [1,20], [-0,878], [0,933]

13 Minha empresa possui uma política de programas de recursos humanos para identificar, desenvolver e reter profissionais altamente capacitados e distribuir este conhecimento através da organização de acordo com a importância do funcionário dentro da estrutura organizacional. [3,50], [1,57], [-0,044], [-0,113]

\section{INTEGRAÇÃO: $\alpha$-Cronbach $-0,927$}

Minha empresa desenvolve e implementa programas de integração das operações dentro da cadeia de

1 suprimento com os clientes e/ou fornecedores com o objetivo de desenvolver parcerias. [3,80], [1,34], [0,097], [-0,041]

Minha empresa define claramente regras e responsabilidades com os seus clientes e/ou parceiros dentro da cadeia de suprimentos. [4,32], [1,13], [-0,439], [-,301]

3 Minha empresa possui diretrizes para o desenvolvimento, manutenção e monitoramento dos relacionamentos dentro da cadeia de suprimentos. [4,21], [1,16], [-0,510], [0,190]

Minha empresa opera dentro da cadeia de suprimentos com os princípios de divisão de ganhos, perdas e riscos com clientes e/ou fornecedores. [3,73], [1,29], [-0,379], [-0,342]

5 Os sistemas de informações logísticos de minha empresa estão sendo expandidos para inserir mais integração nas aplicações. [3,91], [1,23], [-0,070], [-0,537]

6 A base de dados das operações logísticas, planejamento e operação de produção de minha empresa são integradas através de sistemas de informação. [3,79], [1,50], [-0,259], [-0,592]

7 A informação em minha empresa é precisa, em tempo real e formatado para facilitar o seu uso. [3,52], $[1,35],[0,030],[-0,802]$

8 Minha empresa sempre compartilha informações operacionais entre os departamentos. [3,98], [1,09], [$0,844],[0,850]$

9 Minha empresa sempre troca as informações operacionais externamente com clientes e/ou fornecedores previamente selecionados. $[4,00],[1,21],[-0,322],[-0,449]$ 


\section{Roberto Giro Moori, Ester Felix \& Adilson Caldeira}

10

$[3,84],[1,29],[-0,164],[-0,487]$

11

12

Minha empresa tem a habilidade para co

da organização com clientes e/ou fornecedores. [3,55], [1,14], [-0,326], [-0,214]

Os funcionários de minha empresa, assim como os fornecedores e/ou clientes tem facilidade de conexão e

13 um claro entendimento da navegação dentro do sistema de informação de sua empresa. [3,66], [1,23], [$0,787],[0,061]$

14

15 Minha empresa possui políticas e procedimentos de conhecimento comum para a padronização das operações logísticas. [3,80], [1,09], [-0,300], [-0,196]

Minha empresa utiliza constantemente os padrões da indústria para troca de dados. $[3,82],[1,10],[-0,146]$, $[-0,149]$

As operações logísticas de minha empresa são realizadas de modo padronizado. [4,29], [1,02], [-1,034], [1,375]

Minha empresa tem aperfeiçoado constantemente as rotinas e processos nos últimos três anos. [4,50], $[1,03],[-0,627],[-0,226]$

Minha empresa tem conseguido reduzir a complexidade operacional nos últimos três anos. [4,23], [0,972], $[-0,614],[-0,315]$

Minha empresa tem conseguido reduzir a complexidade do canal de vendas nos últimos três anos. [4,32], [0,974], [-0,575], [0,098]

Minha empresa possui programas que reforçam a padronização do desempenho logístico. [3,84], [1,19], [$0,151],[-0,250]$

A consistência de entregas de minha empresa tem aumentado nos últimos três anos. [4,50], [0,953], [$0,522],[0,301]$

Minha empresa alcança constantemente o desempenho logístico estabelecido. [4,50], [1,03], [-0,731], $[0,212]$

\section{AGILIDADE: $\alpha$-Cronbach $-0,902$}

1 As operações logísticas de minha empresa estão focadas no sucesso dos clientes. [4,59], [1,06], [-0,339], [$0,319]$

2 Minha empresa possui flexibilidade para atender a todas solicitações de última hora de seus clientes. $[3,88]$, [1,39], [-0,402], [-0,510]

3 Minha empresa desenvolve relacionamento de negócios específicos para atender individualmente cada cliente nas transações de vendas para o mercado externo. [4,41], [1,30], [-0,562], [-0,428]

4 Minha empresa está apta para atender solicitações específicas dos clientes com soluções pré-planejadas. $[4,41],[1,11],[-0,306],[-0,491]$

5 Minha empresa possui um programa de autorização predeterminado para atender às solicitações especiais dos clientes previamente selecionados. [3,82], [1,38], [-0,447], [-0,495]

6 A operação logística de minha empresa está sincronizada com o serviço de fornecedores para beneficiar os clientes. [4,02], [1,29], [-0,353], [-0,342]

7 Minha empresa tem reduzido a previsão da demanda compartilhando as informações com os clientes. $[3,64],[1,18],[-0,081],[-0,781]$

8 Minha empresa tem aumentado a flexibilidade operacional através da cadeia de suprimentos. $[3,86],[1,15]$, $[-0,156],[-0,284]$

Minha empresa tem desenvolvido programas para facilitar a postergação de produção e/ou entrega do

9 produto manufaturado ou montagem até receber a confirmação ou o pedido final do cliente. [3,89], [1,33], [$0,566],[-0,291]$

\section{MEDIDAS DE DESEMPENHO: $\alpha$-Cronbach $-0,894$}

1 Nos últimos três anos minha empresa tem utilizado com frequência os dados obtidos através dos indicadores de desempenho internos. [4,05], [1,39], [-0,767], [-0,028]

2 Os indicadores de desempenho logístico têm sido usados em minha empresa para avaliação de custos, 2 produtividade, serviço ao cliente, gerenciamento de ativos e qualidade. [4,23], [1,41], [-0,669], [0,006]

3 A qualidade de informações disponíveis para a medição dos indicadores de desempenho em minha empresa é superior há três anos. [4,20], [1,29], [-0,541], [-0,050]

4 Minha empresa utiliza custos ABC na logística. [3,38], [1,37], [-0,103], [-0,565]

5 Os gerentes em minha empresa utilizam indicadores de custo total para tomar decisões. [4,25], [1,25], [$0,552],[0,035]$

6 Minha empresa tem desenvolvido indicadores de desempenho que são utilizados através das relações da 
cadeia de suprimentos. [3,89], [1,30], [-0,255], [-0,702]

Minha empresa realiza o benchmarking externo com empresas do mesmo setor. [3,68], [1,40], [-0,422], [$0,767]$

8 Os gerentes de minha empresa entendem os indicadores de desempenho logístico comparados aos grandes competidores. [3,88], [1,38], [-0,679], [0,022]

9 O benchmark de minha empresa é o melhor em práticas e processos. [3,50], [1,40], [-0,473], [-0,781]

\section{CICLO DE ENTREGA DO PEDIDO: $\alpha$-Cronbach $-0,783$}

Em minha empresa, a escolha do Incoterms está baseada em reduções de custos (fabricação, transporte, embalagem, etc.) visando às necessidades da minha empresa. [4,20], [1,62], [-0,727], [-0,601]

2

Em minha empresa, a venda de produtos ao exterior depende de linha de crédito governamental. [2,29], [1,41], [0,517], [-1,224]

3 Minha empresa investe em informatização que permite a integração da cadeia produtiva, reduzindo a ociosidade de equipamentos, o transporte de material e a mão de obra. [3,79], [1,30], [-0,301], [-0,361]

4 Minha empresa utiliza Incoterms que atendem às necessidades do cliente e da minha empresa. [4,93], $[0,99],[-1,025],[1,195]$

Em minha empresa, as datas de entregas dos produtos ou mudanças na programação de produção são

5 frequentemente comunicadas ao departamento de Vendas de Mercado Externo, para que estes possam informar aos clientes. [4,82], [1,39], [-1,650], [2,201]

$\mathrm{O}$ ciclo do pedido (lead time) de minha empresa poderia ser menor se houvesse planejamento na programação de produção. [3,32], [1,66], [0,153], [-1,161]

7 O ciclo do pedido (lead time) de minha empresa poderia ser menor se houvesse preocupação logística para os produtos destinados ao exterior. [3,13], [1,50], [0,380], [-0,658]

Em minha empresa, a receita de exportações poderia ser aumentada se os produtos fossem embalados de

8 forma mais adequada evitando avarias no transporte e vulnerabilidade do produto. [2,41], [1,47], [0,870], [$0,066]$

9 Minha empresa utiliza a frequência de navios como uma ferramenta para a programação de produção. $[4,02],[1,86],[-0,464],[-1,277]$

A frequência de navios e os bons serviços prestados influenciam na contratação de um armador, a fim de

10 negociar contratos em médio e longo prazo tendo como consequência reduções de custos. [4,46], [1,61], [$0,806],[-0,512]$

Na minha empresa, existem programas de treinamentos para se obter zero de defeitos com o transporte de produtos. [3,57], [1,63], [-0,027], [-1,106]

Em minha empresa, a realização de atividades da cadeia produtiva em locais centralizados facilita o transporte. [4,39], [1,34], [-0,485], [-0,680]

Em minha empresa, as operações de transbordo têm facilitado a carga e a descarga dos produtos para exportação. [3,57], [1,55], [-0,123], [-0,917]

A oferta de serviços de transporte marítimo com maior número de origens e destinos tem reduzido o custo de transportes em minha empresa. [3,79], [1,55], [-0,454], [-0,836]

O frete interno da fábrica até o porto de embarque está sujeito a custos abertos. [3,80], [1,51], [-0,414], [$0,703]$

Em minha empresa, a escolha do modal de transporte leva em conta os efeitos dos impactos sobre as embalagens. [3,05], [1,62], [0,149], [-0,1266]

Em minha empresa, a disponibilidade de contêineres vazios contribui para agilidade do prazo de entrega do produto ao cliente. $[4,00],[1,83],[-0,573],[-1,120]$

18 Em minha empresa, a liberação (despacho) das mercadorias no porto de embarque, é realizada em tempo hábil antes da chegada do navio. [5,27], [1,05], [-2,020], [5,018]

Em minha empresa o tempo utilizado para o despacho da mercadoria tem representado reduções de custos. $[4,20],[1,72],[-0,605],[-0,831]$

20 Minha empresa, possui "Regime Especial" autorizado pela Receita Federal para o despacho das mercadorias. [2,59], [1,91], [0,668], [-1,194]

21 A informatização das atividades portuárias (porto sem papel) reduz consideravelmente o tempo para liberação (despacho) das mercadorias em minha empresa. [3,57], [1,49], [-0,041], [-0,754]

22 A minha empresa considera que a rápida liberação do despacho das mercadorias é um fator agregador de valor em relação a custos. [4,59], [1,51], [-1,128], [0,624]

Minha empresa possui estoques de segurança nos armazéns portuários no Brasil. [2,16], [1,68], [1,236], $[0,095]$

Em minha empresa, as penalidades associadas às sobreestadias (demurrage, detention de contêineres,

24 diárias de caminhões e trens) e atrasos de navios como principais problemas para a obtenção da vantagem competitiva. [4,45], [1,51], [-0,875], [-0,262] 
Minha empresa considera a dragagem portuária como um dos principais empecilhos para que os armadores tragam navios com maior capacidade. [4,48], [1,44], [-1,063], [0,461]

A perda de produtividade no embarque das mercadorias nos navios em minha empresa está relacionada

26 diretamente às regulamentações das funções portuárias (conferentes, estivadores, etc.). [3,30], [1,53], $[0,165],[-0,738]$

A perda de produtividade no embarque das mercadorias nos navios em minha empresa está relacionada

27 diretamente à infraestrutura dos portos, à falta de armazéns, aos equipamentos portuários, ao acesso rodoviário e ou ferroviário, etc. [4,18], [1,45], [-0,617], [-0,339]

A informatização das atividades portuárias (porto sem papel) reduz consideravelmente o tempo de estadia

28 dos navios nos portos agilizando a entrega dos produtos aos clientes de minha empresa. [4,07], [1,48], [$0,409],[-0,533]$

APÊNDICE 2: Regressão linear múltipla, método moderado hierárquico - Efeitos Diretos e Interação sobre o Ciclo de Entrega

\begin{tabular}{|c|c|c|c|c|}
\hline \multirow{2}{*}{ Variáveis } & \multicolumn{4}{|c|}{ ESTÁGIOS } \\
\hline & 1 & 2 & 3 & 4 \\
\hline Intercepto & $\begin{array}{c}1,87 \\
(0,000)\end{array}$ & $\begin{array}{c}1,97 \\
(0,000)\end{array}$ & $\begin{array}{c}1,87 \\
(0,001)\end{array}$ & $\begin{array}{c}1,12 \\
(0,400)\end{array}$ \\
\hline Posicionamento & $\begin{array}{c}0,22 \\
(0,137)\end{array}$ & & & \\
\hline Integração & $\begin{array}{c}0,13 \\
(0,464)\end{array}$ & & & \\
\hline Agilidade & $\begin{array}{c}0,035 \\
0,731)\end{array}$ & & & \\
\hline Medidas de Desempenho & $\begin{array}{c}0,084 \\
(0,444)\end{array}$ & & & \\
\hline Capabilidades Logísticas & & $\begin{array}{c}0,45 \\
(\mathbf{0 , 0 0 0})\end{array}$ & $\begin{array}{c}0,46 \\
(0,000)\end{array}$ & $\begin{array}{c}0,66 \\
(0,054)\end{array}$ \\
\hline Tipo de Produto & & & $\begin{array}{c}0,05 \\
(0,753)\end{array}$ & $\begin{array}{c}0,68 \\
(0,515)\end{array}$ \\
\hline Tipo de Produto x Capabilidades & & & & $\begin{array}{c}-0,17 \\
(0,542)\end{array}$ \\
\hline Estatística F & $\begin{array}{c}5,35 \\
(0,001)\end{array}$ & $\begin{array}{c}21,75 \\
(0,000)\end{array}$ & $\begin{array}{c}10,74 \\
(0,000)\end{array}$ & $\begin{array}{c}7,20 \\
(0,000)\end{array}$ \\
\hline $\mathrm{R}^{2}$ & 0,30 & 0,29 & 0,29 & 0,29 \\
\hline $\mathrm{R}^{2}$ Ajustado & 0,24 & 0,27 & 0,26 & 0,25 \\
\hline Erro padrão de estimativa & 0,511 & 0,499 & 0,503 & 0,506 \\
\hline
\end{tabular}

Nota: Valores entre parênteses representam a significância estatística

Fonte: Dados da pesquisa 